\title{
PENERAPAN AUGMENTED REALITY (AR) DENGAN KOMBINASI TEKNIK MARKER UNTUK VISUALISASI MODEL RUMAH PADA PERUM PRAMUKA GARDEN RESIDENCE
}

\author{
Rusliyawati $^{1)}$, Agus Wantoro' ${ }^{2)}$, Adit Nurmansyah ${ }^{3)}$ \\ ${ }^{1,2}$ Sistem Informasi, Fakultas Teknik dan Ilmu Komputer, Universitas Teknokrat Indonesia \\ ${ }^{3}$ Informatika, Fakultas Teknik dan Ilmu Komputer, Universitas Teknokrat Indonesia \\ 1,2,3 Jl. Z.A Pagaralam, No 9-11, Labuhanratu,Bandarlampung \\ Email: ${ }^{1}$ rusliyawati@teknokrat.ac.id, ${ }^{2}$ aguswantoro@teknokrat.ac.id, ${ }^{3}$ nurmansyahadit97@gmail.co.id
}

\begin{abstract}
The rapid development of information and communication technology has a positive impact on the emergence of information systems supporting technology that can be utilized in many aspects of life such as education, entertainment, tourism and commerce. One of the developing technologies is Augmented Reality (AR) which is able to combine the real and virtual worlds, and can be used as a tool for more attractive promotional media. Pramuka Garden Residence housing currently serves many sales transactions. Data collection conducted in this study using interview techniques, literature review, and questionnaires. The source of data / subjects is the Bandar Lampung community of 30 people, the testing method used is Extrime Programming, Home Application in the garden residence scout housing using Alpha and Beta methods with Augmented Reality which is run on Android. Based on the results of alpha testing using a blackbox, from these data it can be seen that the Design of Augmented Reality Applications for Houses at the Pramuka Garden Residence is running and in accordance with the specified functionality included in the Eligible category. While in beta testing with 30 respondents chose "Yes" from 10 questions so it is said that $100 \%$ of applications can be accepted according to the needs of the respondents. Alpha and Beta test results of the quality of Design and Build Applications for Augmented Reality Houses in the Pramuka Garden Residence Housing based on the data processing in the test was declared very feasible and is expected to be a media for promotional materials, especially the people of Bandar Lampung.
\end{abstract}

Keyword : Augmented Reality (AR), Marking, House

\begin{abstract}
Abstrak
Perkembangan teknologi informasi dan komunikasi yang sangat pesat berdampak positif terhadap munculnya alat-teknologi pendukung sistem informasi yang dapat dimanfaatkan dalam banyak aspek kehidupan seperti pendidikan, hiburan, wisata dan perdagangan. Salah satu teknologi yang berkembang adalah Augmented Reality (AR) yang mampu menggabungkan antara dunia nyata dan maya, dan dapat dijadikan alat untuk media promosi yang lebih menarik. Perumahan Pramuka Garden Residence saat ini melayani banyak transaksi penjualan. Pengumpulan data yang dilakukan pada penelitian ini menggunakan teknik wawancara, tinjauan pustaka, dan kuisioner. Sumber data/subjek yaitu masyarakat Bandar Lampung yang berjumlah 30 orang, metode pengujian yang dilakukan yaitu Extrime Programming, Aplikasi Rumah pada perumahan pramuka garden residence menggunakan metode Alpha dan Beta dengan Augmented Reality yang dijalankan pada Android. Berdasarkan hasil pengujian alpha menggunakan blackbox, dari data tersebut dapat di ketahui bahwa Rancang Bangun Aplikasi Augmented Reality Rumah Pada Perumahan Pramuka Garden Residence berjalan dan sesuai dengan fungsionalitas yang ditetapkan termasuk dalam kategori Layak. Sedangkan pada pengujian beta dengan 30 responden memilih "Ya" dari 10 pertanyaan sehingga dikatakan bahwa 100\% aplikasi dapat diterima sesuai dengan kebutuhan responden tersebut. Hasil pengujian Alpha dan Beta kualitas Rancang Bangun Aplikasi Augmented Reality Rumah Pada Perumahan Pramuka Garden Residence berdasarkan pengolahan data pada pengujian tersebut dinyatakan sangat layak dan diharapkan mampu menjadi media untuk bahan Promosi khususnya masyarakat Bandar Lampung.
\end{abstract}

Kata Kunci : Augmented Reality (AR), Marking, Rumah 


\section{Pendahuluan}

Perkembangan teknologi informasi dan komunikasi yang sangat pesat berdampak positif terhadap munculnya alat-teknologi pendukung sistem informasi yang dapat dimanfaatkan dalam banyak aspek kehidupan seperti pendidikan, hiburan, wisata dan perdagangan [2]. Salah satu teknologi yang berkembang adalah Augmented Reality (AR) yang mampu menggabungkan antara dunia nyata dan maya [3]. AR dapat digunakan membantu visualisasi konsep abstrak untuk pemahaman dan struktur suatu model objek yang dirancang memberikan informasi lebih detail pada pengguna dari objek nyata. Itu berarti teknologi AR dapat dijadikan alat untuk media promosi yang lebih menarik karena dengan memanfaatkan teknologi AR, pemasaran dan pengenalan suatu produk menjadi lebih nyata terutama pada pemasaran bentuk reality suatu model produk yang ada dalam brand yang akan diiklankan [1]

Pertumbuhan investasi property di Indonesia setiap tahun mengalami peningkatan, hal ini dipengaruhi beberapa hal antara lain bertambahnya jumlah kalangan ekonomi menengah di Indonesia sehingga permintaan akan hunian tempat tinggal pun turut bertambah [5].

Strategi pemasaran akan mempengaruhi minat konsumen untuk membeli apabila strategi pemasaran yang dirumuskan dengan promosi, harga, produk, dan tempat memiliki atribut sesuai dengan keinginan konsumen [6]. Penetapan lokasi/outlet dimana konsumen dapat melihat dan memberi produk yang ditawarkan merupakan hal terpenting dalam strategi [4]. Promosi dapat berupa surat kabar, banner, brosur, poster, web-site dan diskon yang ditawarkan menjadi salah satu faktor penentu keberhasilan suatu program pemasaran sebagai daya tarik konsumen untuk berminat membeli [6].

Perumahan Pramuka Garden Residence merupakan perusahaan yang bergerak dibidang distribusi penjualan property perumahanan. Saat ini Garde Residence telah melayani banyak transaksi penjualan perumahan di wilayah Bandar Lampung. Dalam mencapai tujuan mendapatkan daya tarik konsumen Garden Residence melakukan strategi pemasaran berupa promosi melalui brosur ataupun iklan-iklan yang diterbitkan di media massa.

Berdasarkan keadaan yang demikian, perusahaan membutuhkan strategi pemasaran yang tepat sesuai dengan kebutuhan konsumen berdasarkan segmentasi pasar, target, positioning dan marketing yang telah ditetapkan dan berkelanjutan untuk menjangkau setiap lapisan masyarakat dan meningkatkan penjualan. Pemanfaatan teknologi AR dengan tampilan 3D rumah yang terdapat pada brosur diharapkan dapat membantu dalam memudahkan dan memberikan gambaran informasi secara nyata kepada konsumen tentang model dan tipe rumah yang ada di perumahan Pramuka Garden Residence.

\section{Metodelogi}

\section{Konsep AR}

Pada tahap ini ditentukan platform, genre, target audien, pengguna dan objek dari pembuatan aplikasi. Konsep ini ditampilkan pada Tabel 1:

Tabel 1. Deskripsi Konsep Aplikasi $A R$

\begin{tabular}{|c|c|c|}
\hline \multirow{4}{*}{ Judul } & \multirow{4}{*}{$:$} & Rancang \\
\hline & & Augmented Reality Rumah Pada \\
\hline & & Pramuka Garden \\
\hline & & Residence \\
\hline Genre & : & Aplikasi Edukasi \\
\hline Platform & : & Android \\
\hline Software & : & Unity $3 D$, Vuforia, Adobe Photosop \\
\hline Development & & $C C$ dan $3 d s$ Max \\
\hline Target Audiens & $:$ & Masyarakat Bandar Lampung \\
\hline Pengguna & $:$ & 30 Pengguna \\
\hline Objek & : & 3 Dimensi \\
\hline Audio & : & Vokal .mp3 \\
\hline
\end{tabular}

\section{Tahapan Pengembangan}

Tahapan ini menggambarkan tahapan proses dari awal hingga akhir. Berikut ini adalah tahapan pengembangan Augmented Reality untuk model rumah pada Perumahan Pramuka Garden Residence:

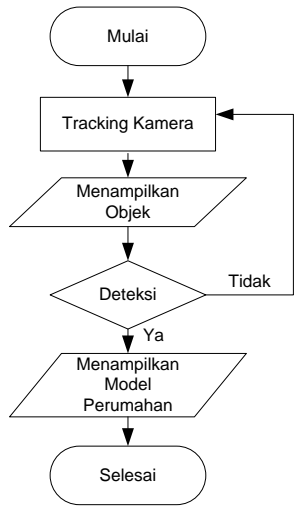

Gambar 1. Tahapan Penelitian

\section{Perancangan (Design)}

Perancangan merupakan tahapan pembuatan spesifikasi pembuatan arsitektur program yang akan dibuat termasuk tampilan dan kebutuhan material atau bahan untuk program.

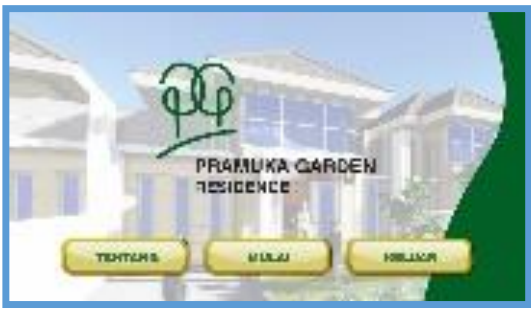

Gambar 2. Rancangan Halaman Utama 


\section{Halaman $A R$ Kamera}

Halaman $A R$ Kamera akan tampil ketika klik tombol mulai pada halaman utama. Pada halaman $A R$ Kamera terdapat tombol kembali untuk kembali ke halaman utama, touch zoom in untuk memperbesar objek 3D, touch zoom out untuk memperkecil objek, tombol rotasi objek 3D otomatis sehingga objek 3D dapat berputar secara otomatis, tombol lokasi untuk menampilkan denah rumah dan spesifikasi bangunan menggunakan suara dan tombol garis kanan untuk menampilkan spesifikasi material bangunan.

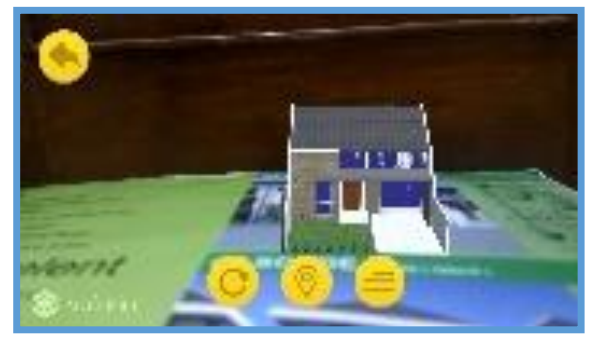

Gambar 3. Tampilan AR Kamera

\section{Perancangan Marker}

Penelitian ini menggunakan teknik marker Augmented reality. Marker adalah media yang digunakan sebagai identitas untuk menampilkan objek 3D oleh aplikasi. berikut contoh dari Marker.

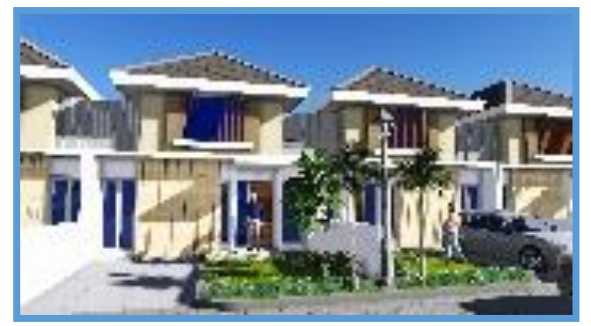

Gambar 4. Tampilan AR Kamera

\section{Pengkodean (Coding)}

Pada tahap ini, perancangan yang sudah dilakukan kemudian diimplementasikan menjadi aplikasi secara utuh. Pengkodean pada aplikasi ini menggunakan software Unity dan bahasa pemrograman C\#. Untuk pembuatan model 3D menggunakan software Blender 3D karena aplikasi ini menghasilkan objek 3D yang baik.

\section{Pengujian (Testing)}

Skenario pengujian aplikasi ini menggunakan Alpha dan Beta. Untuk mengukur kualitas suatu aplikasi $A R$ Perumahan yang telah disesuaikan, maka cukup dengan melakukan aspek pengujian.

\section{Pengujian Alpha}

Pada pengujian Alpha dengan menggunakan teknik black box. Pengujian black-box berfokus pada persyaratan fungsionalitas sistem yang dibangun. Pengujian alpha ini ditunjukan kepada pimpinan perusahaan yang memahami informasi dan spesifikasi dari perumahan, dan 1 pelanggan. Berikut ini skema pengujian alpha dalam contoh tabel pengujian alpha:

Tabel 2. Pengujian Alpha 1

\begin{tabular}{ll}
$\begin{array}{l}\text { Nama } \\
\text { Penguji } \\
\text { Tipe } \\
\text { Pengujian }\end{array}$ & Suhartono, SE. \\
$\begin{array}{l}\text { Nama } \\
\text { Pengujian }\end{array}$ & Menampilkan fungsi dari tombol Menu \\
$\begin{array}{l}\text { Nomor } \\
\text { Pengujian }\end{array}$ & 1 \\
$\begin{array}{l}\text { Deskripsi } \\
\text { Pengujian }\end{array}$ & $\begin{array}{l}\text { Pengujian untuk memastikan bahwa } \\
\text { tombol menampilkan fungsi yang benar } \\
\text { ketika user berinteraksi }\end{array}$ \\
\hline \multicolumn{1}{c}{ Butir Uji }
\end{tabular}

Fungsi ini digunakan user bertujuan agar pengguna dapat melakukan fungsi dan memilih konten yang ada di Menu Utama.

Tabel 3. Hasil Pengujian Alpha 1

\begin{tabular}{|c|c|c|c|}
\hline No & Input & $\begin{array}{c}\text { Spesifikasi } \\
\text { Hasil } \\
\text { Diharapkan } \\
\end{array}$ & $\begin{array}{c}\text { Hasil } \\
\text { Pengujian } \\
\end{array}$ \\
\hline 1 & $\begin{array}{l}\text { Klik } \\
\text { Tombol } \\
\text { Mulai }\end{array}$ & $\begin{array}{l}\text { Menampilkan dan } \\
\text { Membuka } \\
\text { Tampilan AR } \\
\text { Kamera }\end{array}$ & $\begin{array}{l}\operatorname{Diterima}[\sqrt{ }] \\
\operatorname{Ditolak}[]\end{array}$ \\
\hline 2 & $\begin{array}{l}\text { Klik } \\
\text { Tombol } \\
\text { Tentang }\end{array}$ & $\begin{array}{l}\text { Menampilkan dan } \\
\text { Membuka } \\
\text { Informasi } \\
\text { Aplikasi dan } \\
\text { Pembuat }\end{array}$ & $\begin{array}{l}\text { Diterima }[\sqrt{ }] \\
\text { Ditolak }[]\end{array}$ \\
\hline 3 & $\begin{array}{l}\text { Klik } \\
\text { Tombol } \\
\text { Keluar }\end{array}$ & Keluar Aplikasi & $\begin{array}{l}\text { Diterima }[\sqrt{ }] \\
\text { Ditolak [ ] }\end{array}$ \\
\hline
\end{tabular}

Kesimpulan

Berdasarkan hasil pengujian disimpulkan bahwa

Tombol Menu Utama Berjalan Semestinya Benar/Salah 
Tabel 4. Pengujian Alpha 2

\begin{tabular}{ll}
$\begin{array}{l}\text { Nama } \\
\text { Penguji } \\
\text { Tipe } \\
\text { Pengujian }\end{array}$ & Setiawansyah, M.Kom. \\
Nama & Menampilkan fungsi dari tombol pada \\
Pengujian & AR Kamera \\
Nomor & 2 \\
Pengujian & Pengujian untuk memastikan bahwa \\
Deskripsi & $\begin{array}{l}\text { tombol menampilkan fungsi yang benar } \\
\text { Pengujian }\end{array}$ \\
& \multicolumn{1}{c}{ ketika User berinteraksi di scane AR }
\end{tabular}

Fungsi ini digunakan User dengan tujuan agar pengguna dapat melakukan fungsi dan memilih fungsi yang tersedia ada AR

Tabel 5. Hasil Pengujian Alpha 2

\begin{tabular}{|c|c|c|c|c|}
\hline No & \multicolumn{2}{|c|}{ Input } & $\begin{array}{c}\text { Spesifikasi } \\
\text { Hasil } \\
\text { Diharapkan }\end{array}$ & $\begin{array}{c}\text { Hasil } \\
\text { Pengujian }\end{array}$ \\
\hline 1 & \multicolumn{2}{|c|}{$\begin{array}{l}\text { Tombol } \\
\text { Rotasi }\end{array}$} & $\begin{array}{l}\text { Memutar } \\
\text { Objek }\end{array}$ & $\begin{array}{l}\text { Diterima }[\sqrt{ }] \\
\text { Ditolak }[]\end{array}$ \\
\hline 2 & \multicolumn{2}{|c|}{$\begin{array}{l}\text { Klik } \\
\text { Tombol }\end{array}$} & $\begin{array}{l}\text { Menampilkan } \\
\text { Denah }\end{array}$ & $\begin{array}{l}\text { Diterima }[\sqrt{ }] \\
\text { Ditolak }[]\end{array}$ \\
\hline 3 & \multicolumn{2}{|c|}{ Gestur 2 Jari } & $\begin{array}{l}\text { Memperbesar } \\
\text { Dan } \\
\text { Memperkecil } \\
\text { Objek }\end{array}$ & $\begin{array}{l}\text { Diterima }[\sqrt{ }] \\
\text { Ditolak }[]\end{array}$ \\
\hline 4 & $\begin{array}{l}\text { Klik } \\
\text { Suara }\end{array}$ & Ikon & $\begin{array}{l}\text { Mendengarkan } \\
\text { Spesifikasi } \\
\text { Dengan Suara }\end{array}$ & $\begin{array}{l}\text { Diterima }[\sqrt{ }] \\
\text { Ditolak }[]\end{array}$ \\
\hline 5 & \multicolumn{2}{|c|}{$\begin{array}{l}\text { Klik } \\
\text { Tombol } \\
\text { Kembali }\end{array}$} & $\begin{array}{l}\text { Kembali } \\
\text { Aplikasi Ke } \\
\text { Menu Utama }\end{array}$ & $\begin{array}{l}\text { Diterima }[\sqrt{ }] \\
\text { Ditolak }[]\end{array}$ \\
\hline 6 & \multicolumn{2}{|c|}{$\begin{array}{l}\text { Tracking } \\
\text { Image }\end{array}$} & $\begin{array}{l}\text { Kamera } \\
\text { Menampilkan } \\
\text { Image Target }\end{array}$ & $\begin{array}{l}\text { Diterima }[\sqrt{ }] \\
\text { Ditolak }[]\end{array}$ \\
\hline \multicolumn{5}{|c|}{$\begin{array}{l}\text { Berdasarkan hasil pengujian disimpulkan bahwa } \\
\text { Tombol AR Kamera Semestinya Benar/Salah }\end{array}$} \\
\hline \multicolumn{5}{|c|}{ Tabel 6. Pengujian Alpha 3} \\
\hline \multirow{2}{*}{\multicolumn{2}{|c|}{$\begin{array}{l}\text { Nama } \\
\text { Penguji } \\
\text { Tipe } \\
\text { Pengujian } \\
\text { Nama } \\
\text { Pengujian }\end{array}$}} & Dona & jian Fungsional & \\
\hline & & $\begin{array}{l}\text { Menc } \\
\text { dari } 1\end{array}$ & $\begin{array}{l}\text { npilkan asil trac } \\
\text { arker }\end{array}$ & ng image target \\
\hline
\end{tabular}

Nomor

Pengujian

Deskripsi

Pengujian

\section{3}

Pengujian ini untuk memastikan bahwa AR kamera dapat menampilkan objek 3D Animasi dari masing-masing marker Butir Uji

Fungsi ini digunakan User dengan tujuan pengguna dapat melakukan fungsi dan memilih fungsi yang tersedia pada AR

Tabel 7. Hasil Pengujian Alpha 3

\begin{tabular}{|c|c|c|c|}
\hline No & Input & $\begin{array}{c}\text { Spesifikasi } \\
\text { Hasil } \\
\text { Diharapkan } \\
\end{array}$ & $\begin{array}{c}\text { Hasil } \\
\text { Pengujian }\end{array}$ \\
\hline 1 & $\begin{array}{l}\text { Gambar } \\
\text { Marker } 01\end{array}$ & $\begin{array}{l}\text { Menampilkan } \\
\text { Objek 3D } \\
\text { Perumahan } \\
\text { Acasia }\end{array}$ & $\begin{array}{l}\text { Diterima }[\sqrt{ }] \\
\text { Ditolak }[]\end{array}$ \\
\hline 2 & $\begin{array}{l}\text { Gambar } \\
\text { Denah } \\
\text { Acasia }\end{array}$ & $\begin{array}{l}\text { Menampilkan } \\
\text { Objek denah } \\
\text { 3D Rumah } \\
\text { Acasia }\end{array}$ & $\begin{array}{l}\text { Diterima }[\sqrt{ }] \\
\text { Ditolak }[]\end{array}$ \\
\hline 3 & $\begin{array}{l}\text { Gambar } \\
\text { Marker } 03\end{array}$ & $\begin{array}{l}\text { Menampilkan } \\
\text { Objek 3D } \\
\text { Perumahan } \\
\text { Cascade }\end{array}$ & $\begin{array}{l}\text { Diterima }[\sqrt{ }] \\
\text { Ditolak }[]\end{array}$ \\
\hline 4 & $\begin{array}{l}\text { Gambar } \\
\text { Denah } \\
\text { Cascade }\end{array}$ & $\begin{array}{l}\text { Menampilkan } \\
\text { Objek 3D } \\
\text { Denah Rumah } \\
\text { Cascade }\end{array}$ & $\begin{array}{l}\text { Diterima }[\sqrt{ }] \\
\text { Ditolak }[]\end{array}$ \\
\hline 5 & $\begin{array}{l}\text { Gambar } \\
\text { Marker } 05\end{array}$ & $\begin{array}{l}\text { Menampilkan } \\
\text { Objek 3D } \\
\text { Perumahan } \\
\text { Nevada }\end{array}$ & $\begin{array}{l}\text { Diterima }[\sqrt{ }] \\
\text { Ditolak }[]\end{array}$ \\
\hline 6 & $\begin{array}{l}\text { Gambar } \\
\text { Denah } \\
\text { Nevada }\end{array}$ & $\begin{array}{l}\text { Menampilkan } \\
\text { Objek 3D } \\
\text { Denah Rumah } \\
\text { Nevada }\end{array}$ & $\begin{array}{l}\text { Diterima }[\sqrt{ }] \\
\text { Ditolak }[]\end{array}$ \\
\hline 7 & $\begin{array}{l}\text { Gambar } \\
\text { Marker } 07\end{array}$ & $\begin{array}{l}\text { Menampilkan } \\
\text { Objek 3D } \\
\text { Perumahan } \\
\text { Chicago }\end{array}$ & $\begin{array}{l}\text { Diterima }[\sqrt{ }] \\
\text { Ditolak }[]\end{array}$ \\
\hline 8 & $\begin{array}{l}\text { Gambar } \\
\text { Denah } \\
\text { Chicago }\end{array}$ & $\begin{array}{l}\text { Menampilkan } \\
\text { Objek 3D } \\
\text { Denah Rumah } \\
\text { Chicago }\end{array}$ & $\begin{array}{l}\text { Diterima }[\sqrt{ }] \\
\text { Ditolak }[]\end{array}$ \\
\hline
\end{tabular}

Kesimpulan 
Berdasarkan hasil pengujian disimpulkan bahwa Fungsi AR Kamera Berjalan Semestinya Benar/Salah

Berdasarkan hasil pengujian di atas, dapat
disimpulkan bahwa aspek Functional aplikasi Augmented Reality Perumahan Pramuka Garden Recidence memperoleh hasil nilai $100 \%$ dan artinya aplikasi dapat bekerja dengan Baik.

\section{Pengujian Beta}

Pengujian Beta dilakukan di lingkungan pengguna tanpa kehadiran pihak pembangun aplikasi. Pengujian Beta merupakan pengujian yang bersifat langsung di lingkungan yang sebenarnya. Kuesioner pengujian Beta merupakan media yang digunakan pengguna aplikasi untuk memberikan penilaian terhadap aplikasi yang dibangun. Berdasarkan kuesioner tersebut akan dilakukan perhitungan agar dapat diambil kesimpulan terhadap penilaian penerapan aplikasi yang dibangun. Pengujian beta dilakukan terhadap 30 responden dari masyarakan umum.

\section{Nilai Persentase}

$$
=\frac{\text { total skor hasil pengujian }}{\text { skor Ideal }}
$$

Berdasarkan hasil pengujian Transferability pada tabel diatas, maka presentasi uji aspek Transferability dapat dihitung sebagai berikut:

$$
\begin{aligned}
& =\frac{30}{30} \times 100 \\
& =100 \%
\end{aligned}
$$

Pengujian Beta Rancang Bangun Aplikasi Augmented Reality Rumah Pada Perumahan Pramuka Garden Residence dilakukan menggunakan user atau penggunakan secara langsung terhadap masyarakat dengan mengambil 30 responden memilih "Ya" dari 10 pertanyaan sehingga dikatakan bahwa $100 \%$ aplikasi dapat diterima sesuai dengan kebutuhan responden tersebut.

\section{Kesimpulan}

Berdasarkan uraian yang telah dipaparkan, dapat diambil kesimpulan sebagai berikut:

1. Aplikasi Rancang Bangun Augmented Reality Rumah pada Perumahan Pramuka Garden Residence dikembangkan dengan software atau engine menggunakan unity $3 D$ dan vuvoria sebagai asset plugin pada Augmented Reality dan untuk pemodelan objek 3D menggunakan Software Blender sebagai editornya.

2. Aplikasi Rancang Bangun Augmented Reality Rumah pada Perumahan Pramuka Garden Residence yang dibuat berisi informasi dan spesifikasi tentang tipetipe rumah disertai informasi dalam bentuk audio, sehingga pengguna dapat informasi dalam bentuk visual dan dapat berinteraksi langsung dengan objeknya.

3. Berdasarkan pengujian alpha dengan menggunakan blackbox, dapat diketahui bahwa rancang bangun aplikasi AR pada Garden Residence berjalan dan sesuai dengan fungsionalitas yang ditetapkan termasuk dalam kategori layak. Sedangkan pada pengujian beta dengan 30 responden memilih "Ya" dari 10 pertanyaan sehingga dikatakan bahwa $100 \%$ aplikasi Dapat Diterima sesuai dengan kebutuhan responden tersebut.

\section{Daftar Pustaka}

[1] Amar Ahmad. 2012. Perkembangan Teknologi Komunikasi dan Informasi: Akar Revolusi Dan Berbagai Standarnya.

[2] Azuma, R., 1997. A Survey of Augmented Reality. Presence : Teleoperator and Virtual Environments, pp.355- 385 .

[3] Joefrie, YY, Anshori, Y. 2011. Teknologi Augmented Reality. Jurnal Ilmiah (Mektek).

[4] Winardi. 2012. Manajemen Penjualan. Edisi Pertama. Bandung

[5] Siti Murtiningsih. (2005). Analisis Dampak Guncangan Variabel Makro Terhadap Investasi Bisnis Properti Di Indonesia. Departemen Ilmu Ekonomi, IPB.

[6] Tjiptono, Fandy. 2004. Manajemen Pemasaran Jasa, Andi, Yogyakarta. 